\title{
STUDI SIFAT FISIKOKIMIA MEMBRAN KITOSAN TERMODIFIKASI HEPARIN DAN POLIETILEN GLIKOL (PEG)
}

\author{
Retno Ariadi Lusiana ${ }^{1 *}$, Diana Pratiwi Rusendi ${ }^{1,}$ Didik Setiyo Widodo $^{1}$, Abdul Haris ${ }^{1}$, Ahmad \\ Suseno $^{I}$, Gunawan ${ }^{I}$ \\ ${ }^{1}$ Departemen Kimia FSM Universitas Diponogoro, Semarang Jawa Tengah \\ retno.lusiana@live.undip.ac.id
}

Artikel Info
Diterima
tanggal
31.08 .2019
Disetujui
publikasi
tanggal
31.10.2019
Kata kunci:
Biopolymer,
kitosan, PEG

\section{ABSTRACT}

Membrane material is intended to produce membranes with suitable characteristics such as small pores that are uniform, mechanically strong, and have high pressure resistance. Chitosan is a biopolymer that can be used as a membrane material This research develops chitosan based membrane and analyzes the physical and chemical characteristics of chitosan membrane and modified chitosan membrane. The membrane is made through a graft reaction method and PEG integration. The success of the modified reaction was analyzed by FTIR and physical characteristics were analyzed through tests of water absorption, water development, porosity, $\mathrm{pH}$ resistance, and hydrophilicity. FTIR spectra obtained showed that chitosan membrane modification was successfully carried out. Modification through the integration of PEG and graft reaction can increase the percentage of water absorption, development power, porosity, and increase membrane hydrophilicity. Meanwhile, membrane resistance under various $\mathrm{pH}$ conditions, modified chitosan membrane is higher than chitosan membrane.

\section{PENDAHULUAN}

Membran didefinisikan sebagai suatu media berpori, berbentuk film tipis, bersifat semipermeabel yang berfungsi untuk memisahkan partikel dengan ukuran molekuler (spesi) dalam suatu sistem larutan. Spesi yang memiliki ukuran yang lebih besar dari pori membran

doi: http://dx.doi.org/10.23960/aec.v4.i2.2019.p01-13

Anal.Environ.Chem.Anal.Environ.Chem. 
akan tertahan sedangkan spesi dengan ukuran yang lebih kecil dari pori membran akan lolos menembus pori membran (Burggraaf, et. al., 2000, Kiswandono, 2016). Dalam kegunaannya, suatu membran harus memiliki pori-pori kecil yang seragam, kuat secara mekanik, bersifat hidrofilik, dan mempunyai ketahanan pada tekanan tinggi (Lusiana, et. al., 2019). Biopolimer yang potensial sebagai material membran adalah kitosan (CS). Dalam lingkungan asam, gugus amina kitosan terprotonasi menjadi $-\mathrm{NH}_{3}{ }^{+}$, yang membuat kitosan membentuk larutan homogen. Sifat ini menjadikan kitosan mudah dibuat menjadi film tipis membran melalui metoda inversi fasa. Selain itu, kitosan bersifat inert, biodegradable, regeneratif dan hidrofilik. Namun, membran kitosan juga memiliki kelemahan, seperti kekuatan mekanik yang rendah dan kurangnya sisi aktif yang dapat meningkatkan fungsi kerja membran. Untuk mengatasi kelemahan tersebut diperlukan modifikasi, baik secara struktur maupun permukaan. Menurut (Lusiana, et. al., 2016), terdapat tiga cara yang dapat dilakukan untuk memodifikasi kitosan yaitu melalui reaksi taut silang (crosslinking), reaksi cangkok (grafting), dan pemaduan (blending).

(Zeng et. al., 2004) mempelajari paduan PEG dan kitosan untuk membuat struktur mikropori. Adanya PEG dapat meningkatkan kekuatan mekanik, hidrofilisitas membran karena peningkatan interaksi dan keterikatan polimer. (Huang, et. al., 2011) memodifikasi kitosan dengan heparin untuk mendapatkan membran dengan afinitas dan fluks yang tinggi. (Lusiana, et. al., 2019, Lusiana dan Pranoto, 2018) juga mempelajari reaksi cangkok heparin pada membran kitosan. Dikemukakan bahwa reaksi cangkok menyebabkan masuknya gugus $-\mathrm{SO}_{3} \mathrm{H}$ dalam struktur kitosan yang dapat menghasilkan membran lebih polar dan hidrofilik. Modifikasi pemaduan PEG dan teknik cangkok pada membran kitosan diharapkan mampu meningkatkan karakteristik fisik dan hidrofilisitas membran.

\section{METODE}

\section{Alat dan Bahan}

Alat utama yang digunakan dalam penelitian ini adalah alat gelas standar penelitian, cawan petri, neraca analitik, oven, stirer, desikator, thickness meter, Ultrasonic Homogenizer, dan instrumen FTIR (Perkin Elmer). Bahan diantaranya adalah kitosan (Merck, BM 499.000 g/mol), Polietilen glikol (Merck, BM 4000 g/mol), asam asetat glasial p.a (Merck), Heparin 5000 IU dan akuades.

doi: http://dx.doi.org/10.23960/aec.v4.i2.2019.p01-13

Anal.Environ.Chem.Anal.Environ.Chem. 


\section{Prosedur}

Kitosan dan polietilen glikol ditimbang dan dilarutkan dalam asam asetat $1 \%$ lalu distirer selama 24 jam kemudian. Selanjutnya membran dicetak menggunakan cawan petri, dengan masing-masing cawan dituangkan larutan sampel lalu dikeringkan dalam oven pada suhu 46-50 ${ }^{\circ} \mathrm{C}$ selama 16 jam. Pembuatan membran kitosan tercangkok heparin paduan PEG dibuat dalam perbandingan mol tetap antara kitosan dan PEG serta dalam 3 variasi konsentrasi hepari (Tabel 1). Membran yang sudah kering dilepaskan dan dicuci dengan $\mathrm{NaOH} \mathrm{0,03} \mathrm{M}$ dan akuades sampai netral. Membran yang dihasilkan digunakan untuk uji karaktersisasi fisika dan kimia serta transpor glukosa selama 6 jam, konsentrasi awal dan akhir diukur menggunakan spektrofotometer UV-Vis pada panjang gelombang tertentu.

Tabel 1. Perbandingan kitosan dan heparin metode reaksi langsung

\begin{tabular}{lccc}
\hline Jenis Material & $\begin{array}{c}\text { Kitosan } \\
\text { (g) }\end{array}$ & $\begin{array}{c}\text { Heparin } \\
\text { (IU) }\end{array}$ & $\begin{array}{c}\text { PEG } \\
\text { (g) }\end{array}$ \\
\hline CS (A1) & 1,5 & - & - \\
CS/PEG (B1) & 1,5 & - & 0,0375 \\
CS/PEG-Hep 50 iu (C1) & 1,5 & 50 & 0.0375 \\
CS/PEG-Hep 100 iu (C2) & 1,5 & 100 & 0.0375 \\
CS/PEG-Hep 200 iu (C3) & 1,5 & 200 & 0.0375 \\
CS/PEG-Hep 50 iu immersi (D1) & 1,5 & 50 & 0.0375 \\
CS/PEG-Hep 100 iu immersi (D2) & 1,5 & 100 & 0.0375 \\
CS/PEG-Hep 200 iu immersi (D3) & 1,5 & 200 & 0.0375 \\
\hline
\end{tabular}

\section{HASIL DAN PEMBAHASAN}

\section{Sintesis Membran Paduan (CS- PEG/Hep)}

Reaksi paduan antara kitosan dengan PEG dilakukan dengan melarutkan dalam asam asetat dan membran dibuat dengan proses inversi fasa. Inversi fasa adalah suatu metode yang digunakan dalam pembuatan membran polimer, dimana kitosan dan PEG dalam bentuk serbuk padatan diubah ke bentuk larutan dan kembali diubah ke bentuk padatan kembali melalui proses penguapan (Lusiana, et. al., 2016).

Reaksi pencangkokkan antara CS-PEG dengan heparin dilakukan dengan adanya katalis asam, pada temperatur $50{ }^{\circ} \mathrm{C}$ selama \pm 24 jam. Keberhasilan reaksi tersebut dibuktikan menggunakan uji gugus fungsi (FTIR) seperti ditunjukkan pada Gambar 1. Spektra spesifik 
kitosan ditunjukkan oleh adanya serapan bilangan gelombang $3380 \mathrm{~cm}^{-1}$ yang menunjukkan regangan $\mathrm{O}-\mathrm{H}$ gugus $-\mathrm{OH}$ kitosan, serapan pada $2854 \mathrm{~cm}^{-1}$ menunjukkan adanya regangan $\mathrm{C}-\mathrm{H}$ $\mathrm{sp}^{3}$. Spektra serapan $1580 \mathrm{~cm}^{-1}$ dan $1620 \mathrm{~cm}^{-1}$ merupakan regangan kembar menunjukkan tekukan $\mathrm{N}-\mathrm{H}$ dari gugus $\mathrm{N}-\mathrm{H}$ primer. Kemudian serapan $1040 \mathrm{~cm}^{-1}$ menunjukkan serapan khas gugus $\mathrm{C}-\mathrm{O}$ pada struktur kitosan.

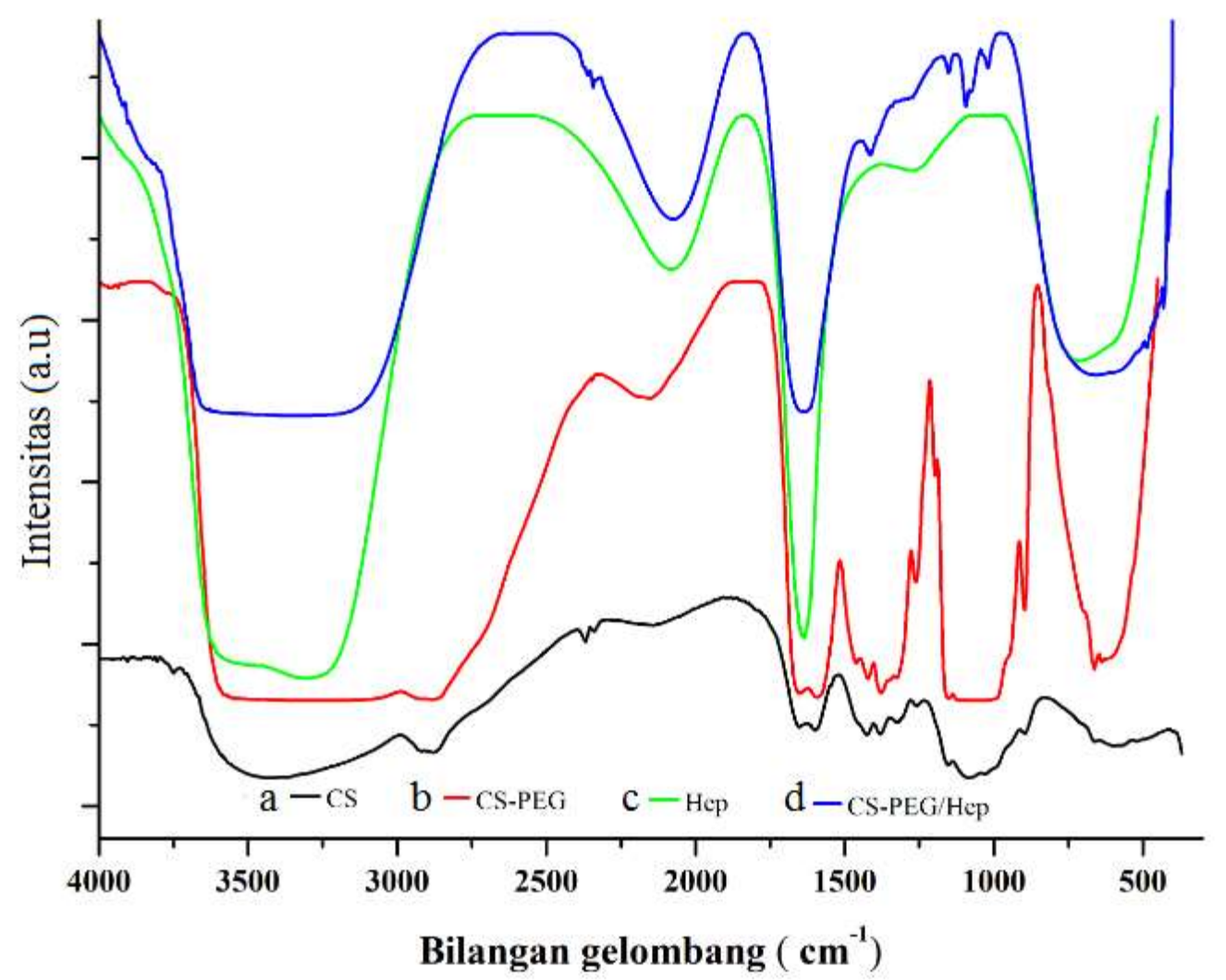

Gambar 1 Spektra IR (a) Kitosan (b) CS-PEG (c) Heparin (d) CS-PEG/Hep

Gugus spesifik pada heparin di tunjukkan oleh serapan pada $3358 \mathrm{~cm}^{-1}$ yang mengindikasikan adanya regangan $-\mathrm{OH}$ pada gugus karboksilat. Serapan pada daerah $1654 \mathrm{~cm}^{-1}$ mengindikasikan adanya karbonil $(\mathrm{C}=\mathrm{O})$ dan serapan pada daerah $779 \mathrm{~cm}^{-1}$ merupakan serapan khas gugus $-\mathrm{OSO}_{3}{ }^{-}$heparin.

Gugus spesifik pada membran CS-PEG ditunjukkan oleh serapan pada daerah $3292 \mathrm{~cm}^{-1}$ yang mengindikasikan adanya peregangan gugus $-\mathrm{OH}$ dari PEG. Puncak serapan pada daerah 
$2151 \mathrm{~cm}^{-1}$ menunjukkan adanya $\mathrm{CH}_{2}$. Serapan 1591 dan $1650 \mathrm{~cm}^{-1}$ merupakan regangan dari gugus N-H primer. Serapan pada daerah $1000 \mathrm{~cm}^{-1}$ menunjukkan adannya pergesaran gugus CO kitosan.

Reaksi cangkok heparin pada membran CS-PEG ditunjukkan pada spektra IR dengan adanya pergesaran regangan -OH dari spektra kitosan berturut-turut $3527 \mathrm{~cm}^{-1}$ Hal ini menyatakan terjadi pergesaran gugus $-\mathrm{OH}$ yang semakin meruah sehingga telah terjadi reaksi cangkok antara gugus $-\mathrm{NH}_{2}$ pada kitosan dengan gugus - $\mathrm{OSO}_{3}$ - dari heparin. Pergesaran tekuk $\mathrm{N}-\mathrm{H}$ primer dari daerah serapan $1580 \mathrm{~cm}^{-1}$ dan $1620 \mathrm{~cm}^{-1}$ pada spektra kitosan menjadi $1658 \mathrm{~cm}^{-}$ 1. Kerberhasilan reaksi cangkok heparin dapat dilihat dari perubahan dua puncak pada gugus N$\mathrm{H}$ primer pada kitosan menjadi 1 puncak. Hal ini juga mempertegas dengan adanya perubahan amina primer menjadi amina sekunder atau tersier dengan munculnya spektra di daerah serapan $1428 \mathrm{~cm}^{-1}$.

Dari data spektra-spektra tersebut, dapat dijelaskan mekanisme reaksi antara CS, CS-PEG dan CS-PEG/Hep melalui tahap reaksi : pertama terjadi protonisasi gugus $-\mathrm{NH}_{2}$ - pada kitosan oleh proton yang berasal dari asam asetat dan pada tahap ini reaksi berlangsung cepat (Gambar 2). Akibatnya atom $-\mathrm{N}$ pada kitosan menjadi bermuatan positif sehingga sangat mudah diserang oleh pasangan elektron bebas yang dimiliki oleh gugus $-\mathrm{OSO}_{3}-,-\mathrm{COOH}, \mathrm{O}_{3} \mathrm{SOH}_{2} \mathrm{C}-,-\mathrm{NHSO}_{3} \mathrm{H}$ heparin. Tahap kedua terbentuk struktur kitosan paduan PEG yang digambarkan melalui tipe reaksi ikatan hidrogen yaitu gugus $\mathrm{OH}$ pada PEG dengan 1 rantai kitosan yakni gugus $-\mathrm{OH}-$ $\mathrm{CH}_{2}$. Tahap ketiga adalah reaksi cangkok heparin pada CS-PEG. Reaksi ini berlangsung lambat karena struktur kitosan yang telah tercangkok heparin digambarkan melalui reaksi intermolekuler yaitu cangkok heparin pada dua rantai kitosan. Ion $\mathrm{H}^{+}$berupa katalis yang berasal dari tahap awal terbentuk lagi pada tahap reaksi akhir sehingga struktur kitosan lebih bermuatan negatif dan akan menambah sisi aktif pada membran untuk melakukan transpor permeat melalui ikatan hidrogen.

\section{Uji Ketebalan dan Berat Membran}

Kandungan massa zat dari membran mencirikan membran mempunyai berat dan tebal berbeda. Perbedaan nilai ketebalan membran seiring dengan penambahan variasi komposisi paduan membran. Hasil pengukuran tebal dan berat pada berbagai membran dapat dilihat pada Tabel 2.

doi: http://dx.doi.org/10.23960/aec.v4.i2.2019.p01-13

Anal.Environ.Chem.Anal.Environ.Chem. 
Tahap 1. Kitosan mengalami protonasi karena suasana asam dari asam asetat.
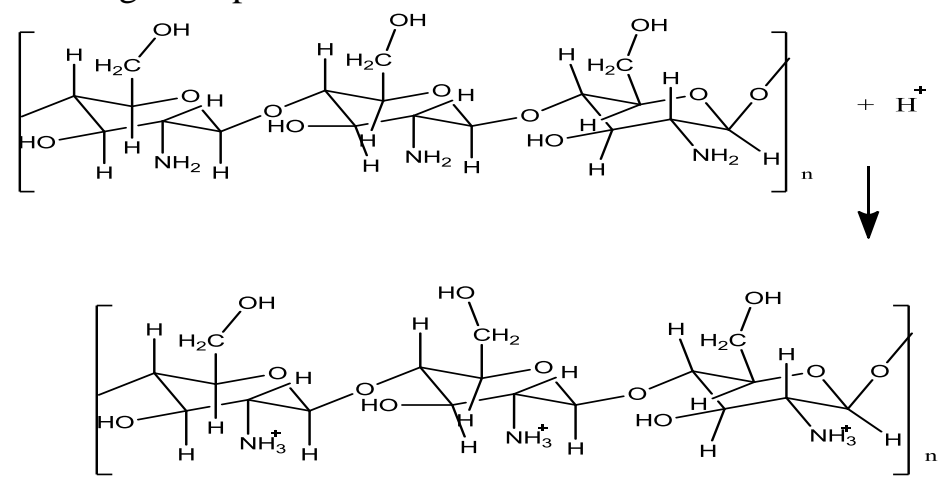

Tahap 2 Pemaduan kitosan dengan PEG

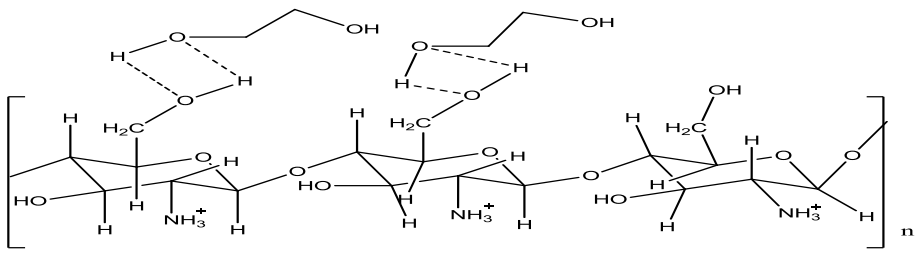

Tahap 3. Reaksi pencangkokan CS-PEG menggunakan heparin

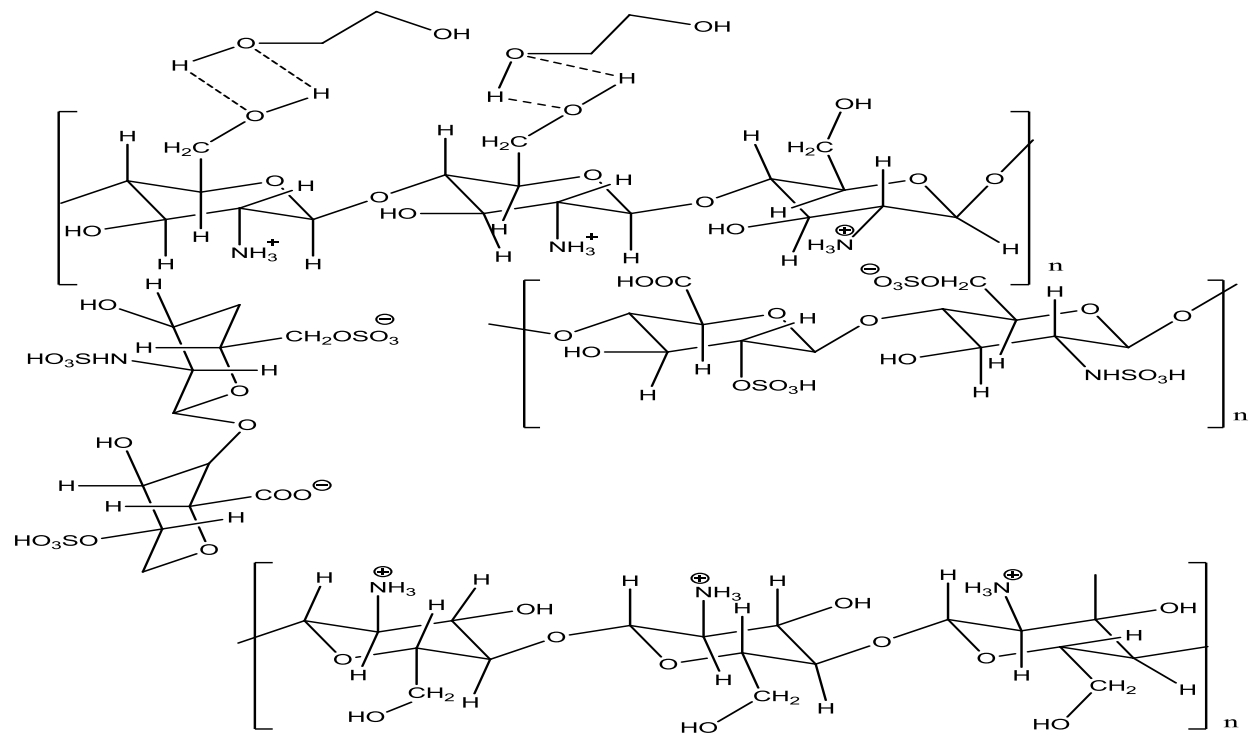

Gambar 2. Mekanisme reaksi antara kitosan-PEG dan heparin

Membran mempunyai berat dan tebal yang berbeda mengindikasikan kandungan massa zat dari membran. Semakin banyak kandungan massa akan meningkatkan berat dan tebal membran. Berat membran kedua metode tersebut terjadi kenaikan dibanding membran kitosan murni dikarenakan adanya penambahan komposisi penyusun membran. 
Tabel 1 Hasil pengukuran ketebalan dan berat pada membran

\begin{tabular}{ccccc}
\hline \multirow{2}{*}{$\begin{array}{c}\text { Tipe } \\
\text { Membran }\end{array}$} & \multicolumn{3}{c}{ Volume larutan pembuat membran } \\
\cline { 2 - 5 } & \multicolumn{2}{c}{$5 \mathrm{~mL}$} & \multicolumn{2}{c}{$10 \mathrm{~mL}$} \\
\cline { 2 - 5 }$(\mathrm{mg})$ & $\begin{array}{c}\text { Terat } \\
(\mu \mathrm{m})\end{array}$ & $\begin{array}{c}\text { Berat } \\
(\mathrm{mg})\end{array}$ & $\begin{array}{c}\text { Tebal } \\
(\mu \mathrm{m})\end{array}$ \\
\hline A1 & 65,3 & 60,0 & 129,2 & 91,7 \\
B1 & 67,5 & 64,3 & 132,3 & 103,3 \\
C1 & 68,2 & 71,1 & 135,9 & 115,2 \\
C2 & 70,5 & 81,7 & 138,5 & 123,3 \\
C3 & 78,7 & 83,3 & 148,5 & 126,7 \\
D1 & 67,6 & 70,0 & 126,0 & 111,0 \\
D2 & 68,1 & 75,0 & 130,1 & 116,8 \\
D3 & 72,3 & 80,0 & 134,6 & 121,8 \\
\hline
\end{tabular}

\section{Uji Biodegradasi}

Uji biodegradasi dilakukan pada semua jenis membran dengan menanamnya di dalam tanah berkompos selama 8 minggu. Semua membran ditimbang, dibasahi dengan air dan ditanam pada kedalaman yang sama. Setiap minggu semua membran diambil dan ditimbang untuk mengetahui penurunan berat membran. Hasil uji biodegradasi membran dapat dilihat pada Gambar 3.

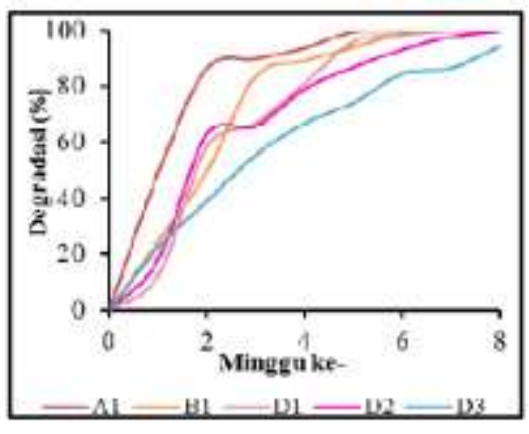

a

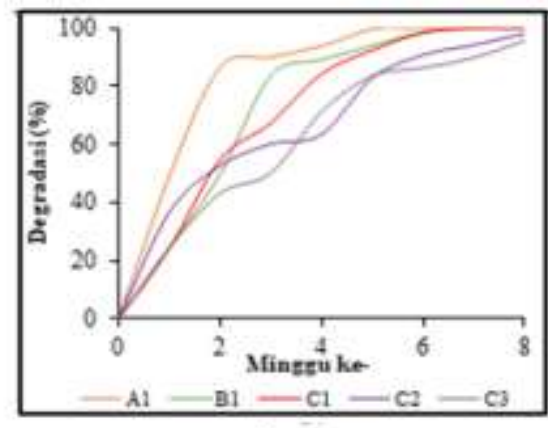

b

Gambar 2. Grafik presentase biodegradasi membran (a) reaksi langsung dan (b) reaksi immersi

Laju degradasi membran kitosan murni lebih cepat dibandingkan membran modififikasi. Hal ini dimungkinkan dengan adanya PEG yang merupakan polimer sintesis dan adanya heparin 
yang memiliki gugus $-\mathrm{SO}_{3} \mathrm{H}$ juga yang akan memperlambat degradasi membran dikarenakan pada degredasi membran modifikasi, bakteri harus mengenal gugus fungsi baru sehingga baru bisa menghancurkan membran. Meningkatnya konsentrasi heparin pada penambahan kitosan membuat membran membutuhkan waktu lebih lama untuk degradasi.

\section{Uji Ketahanan terhadap pH}

Uji pH dilakukan untuk mengetahui ketahanan membran pada range $\mathrm{pH}$ 3, 5, 7, 9 dan 11. Membran direndam dalam larutan pH selama 6 jam. Semua membran ditimbang sebelum (Wo) dan sesudah direndam (Wt) larutan $\mathrm{pH}$. Penurunan berat sebelum dan sesudah perendaman menjadi faktor penentu ketahanan $\mathrm{pH}$ membran (Wt-Wo). Uji ketahanan terhadap $\mathrm{pH}$ pada semua membran menunjukkan hampir tidak ada pengurangan berat membran setelah perendaman selama 6 jam pada $\mathrm{pH} 7-11$, pada pH 3 dan 5, membran larut dan mengalami kerusakan. Hal ini menunjukkan bahwa membran tidak tahan terhadap kondisi $\mathrm{pH}$ yang sangat asam karena kembali melarut dalam lingkungan asam. Modifikasi terhadap kitosan dengan heparin, menambah ketahanan $\mathrm{pH}$ membran.

\section{Uji Hidrofilisitas Membran}

Uji hidrofilisitas menggunakan metode sessile drop dilakukan dengan meneteskan cairan pada permukaan membran kemudian pengamatan dilakukan dengan menggunakan mikroskop untuk melihat sudut yang dihasilkan antara cairan dan membran.
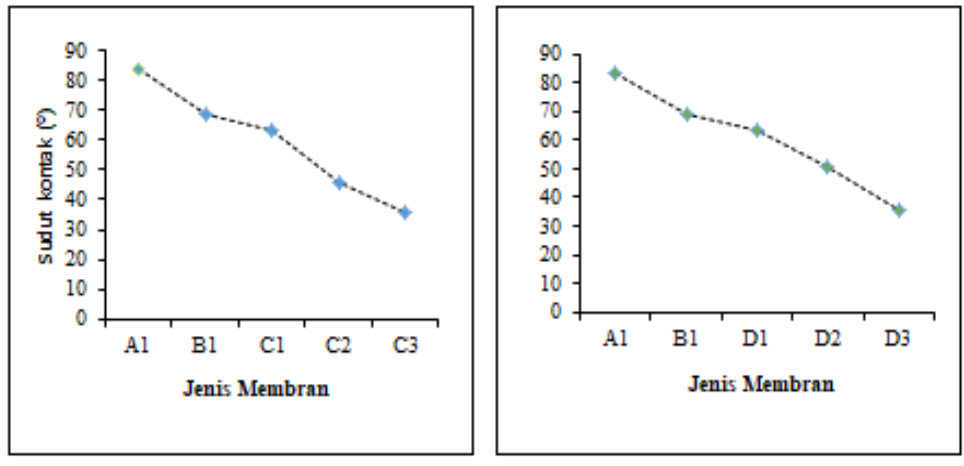

Gambar 3. Grafik hidrofilisitas (a) membran reaksi langsung (b) reaksi immersi 
Penurunan sudut kontak pada membran modifikasi baik dengan reaksi langsung maupun immersi disebabkan karena penambahan heparin meningkatkan sifat hidrofilisitas membran, semakin tinggi konsentrasi heparin yang ditambahkan maka tingkat hidrofilisitas membran meningkat dan sudut kontak semakin kecil. Hal ini disebabkan karena heparin memiliki gugus hidroksil yang meruah dan gugus-gugus elektronegatif lain seperti $\mathrm{SO}_{3}^{-}$yang mampu mengadakan ikatan hidrogen sehingga hidrofilisitas membran meningkat.

\section{Uji Serapan terhadap Air}

Uji serapan terhadap air bertujuan untuk mengetahui kemampuan membran dalam menyerap air. Ketika membran kontak dengan cairan, maka terjadi pengembangan yang disebabkan adanya termodinamika yang bersesuaian antara rantai polimer dan cairan serta adanya gaya tarik yang disebabkan efek ikatan silang yang terjadi pada rantai polimer dalam air.

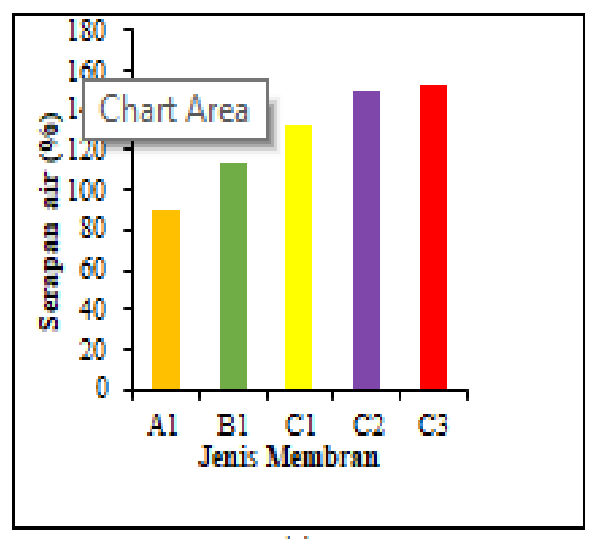

(a)

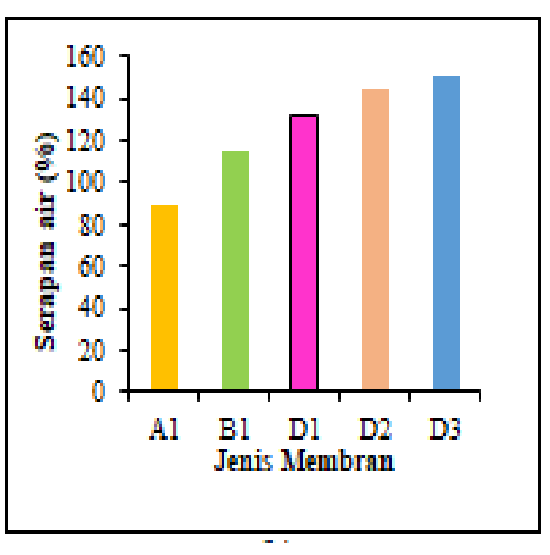

(b)

Gambar 4. Grafik persentase serapan air pada membran (a) reaksi langsung (b) reaksi immersi

Kenaikan persentase serapan air pada membran disebabkan adanya penambahan PEG yang memiliki gugus $-\mathrm{OH}$ yang bersifat hidrofilik sehingga menambah hidrofilisitas membran yang menyebabkan daya serap air meningkat. Penambahan konsentrasi heparin melalui reaksi cangkok baik metode langsung maupun immersi, semakin besar konsentrasi heparin yang ditambahkan maka terjadi kenaikan persentase serapan air pada membran.

\section{Uji Pengembangan Membran}

Uji swelling (pengembangan) pada membran bertujuan untuk memprediksi ukuran zat yang bisa terdifusi ke dalam membran, ditunjukkan pada Gambar 5. Penambahan material lain 
baik melalui pemaduan dengan PEG dan cangkok heparin dengan variasi konsentrasi yang memiliki gugus - $\mathrm{OH}$ dan $\mathrm{SO}_{3}{ }^{-}$yang melimpah sehingga menambah sifat hidrofilisitas membran, sehingga baik pengembangan dan daya serapan air pada membran paduan tercangkok heparin semakin mengalami peningkatan. Hasil ini sesuai dengan penelitian (Lusiana et. Al., 2019).

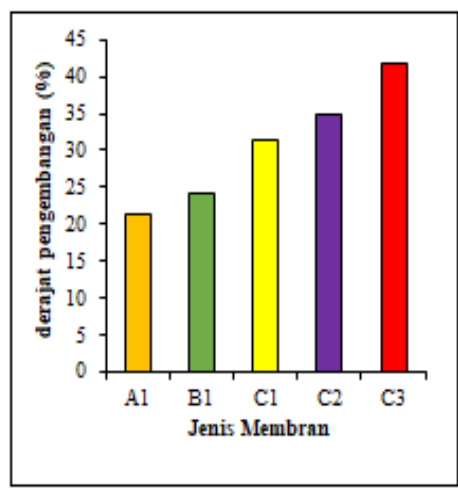

(a)

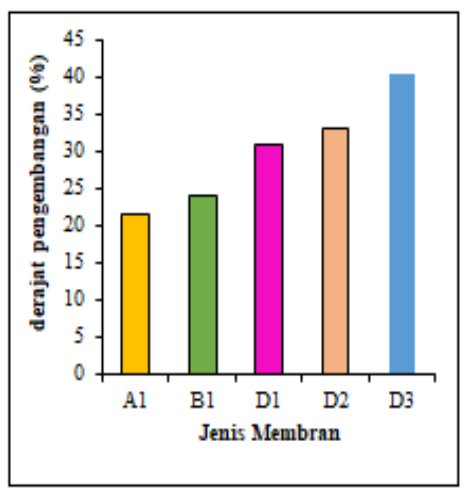

(b)

Gambar 5. Grafik derajat pengembangan membran (a) reaksi langsung (b) reaksi immerse

\section{Uji Porositas Membran}

Pengukuran porositas membran bertujuan untuk mengetahui volume ruang kosong per luasan area diantara material dalam membran.

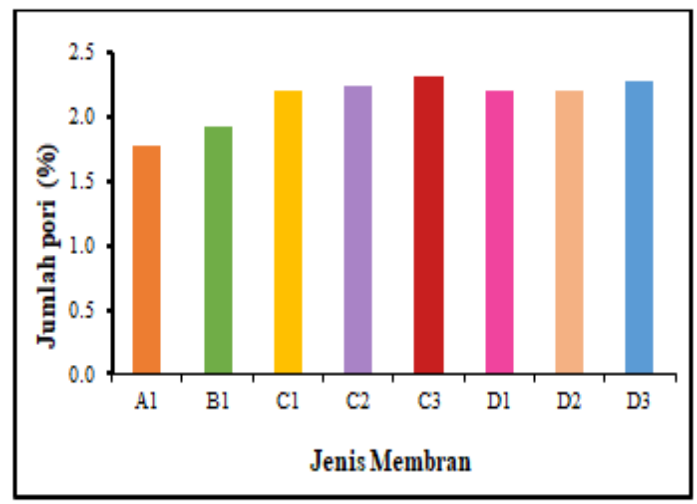

Gambar 6. Grafik persentase porositas membran

Adanya gugus $-\mathrm{OH}$ yang hidrofil mengakibatkan membran bersifat lebih hidrofil sehingga adanya proses inversi fasa pada pelarut asam encer memudahkan peningkatan porositas membran. Hal ini sesuai dengan hasil penelitian dari (Martins et. Al., 2012). Membran modifikasi 
mengalami peningkatan juga karena adanya penambahan material lain atau gugus aktif seperti $\mathrm{SO}_{3}{ }^{-}$yang menambah porositas membran melalui pemanduan membran dan reaksi taut silang sehingga meningkatkan persentase porositas membran (Gambar 6). Porositas merupakan salah satu faktor yang dapat mempengaruhi kinerja membran. Besar kecilnya pori yang dihasilkan akan mempengaruhi kinerja membran dalam penentuan nilai fluks air.

\section{Uji Kekuatan Tarik dan Persentase Elongasi}

Uji kuat tarik pada membran bertujuan untuk mengetahui kekuatan mekanik membran apabila diberikan beban tertentu. Membran C2 mempunyai elastisitas paling tinggi bila dibandingkan dengan membran modifikasi lainnya. Hal ini dikarena adanya komposisi konsentrasi heparin yang optimum sehingga bersifat elastis dan kuat secara mekanik. Peningkatan sifat mekanik membran, diharapkan membran tersebut dapat menahan tekanan air pada saat proses transpor. Perbandingan regangan dan tekanan pada membran memberikan karateristik mekanik tersendiri dengan adanya penambahan PEG dan variasi konsentrasi heparin.

Tahap pertama membran mengalami penurunan $40-100{ }^{\circ} \mathrm{C}$ yang mengindikasikan kehilangan molekul air. Penurunan massa yang sangat siginfikan terjadi pada suhu $200-400^{\circ} \mathrm{C}$ yang mengindikasikan adanya depolimerisasi dan dekomposisi struktur aromatik kitosan. Dibuktikan dengan Gambar 7 menunjukkan bahwa penurunan massa membran kitosan dan modifikasi melalui tahap endotermik. Tahap endotermik ini dimulai dengan material terhidrasi, dehidrasi menjadi proses pertama yang terjadi pada pemanasan dan ditunjukkan oleh suatu endoterm. Material terdehidrasi mengalami transisi polimorfik, yang juga endoterm, pada suhu yang lebih tinggi sehingga melalui dua tahap endotermik.

Tabel 4 menujukkan bahwa membran modifikasi mengalami dekomposisi lebih cepat dibandingkan dengan membran kitosan. Hal ini berarti membran dengan paduan PEG dan cangkok heparin menyebabkan keteraturan dan keseragaman jarak sehingga proses pemutusan ikatan menjadi lebih mudah dan menurunkan stabilitas termal membran modifikasi.

\section{Uji Fluks}

Uji fluks membran terhadap air bertujuan untuk mengetahui sifat permeabilitas membran. Nilai fluks membran modifikasi mengalami peningkatan dari membran kitosan dikarenakan adanya penambahan PEG meningkatkan porositas membran dan reaksi cangkok heparin yang 
membuat membran semakin hidrofil dibuktikan dengan sudut kontak masing-masing membran modifikasi variasi heparin sehingga fluks akuades mengalami peningkatan.Hasil yang sama didapatkan oleh (Huang et. Al.,2011).

Tabel 4. Tahap penurunan massa pada berbagai membran

\begin{tabular}{ccccccc}
\hline & \multicolumn{3}{c}{ Tahap I } & \multicolumn{3}{c}{ Tahap II } \\
\cline { 2 - 7 } Membran & $\mathrm{T}\left({ }^{\circ} \mathrm{C}\right)$ & $\begin{array}{c}\text { Penurunan } \\
\text { Mas5a } \\
(\%)\end{array}$ & $\begin{array}{c}\text { Puncak } \\
\text { Endotermik } \\
\left({ }^{\circ} \mathrm{C}\right)\end{array}$ & $\mathrm{T}\left({ }^{\circ} \mathrm{C}\right)$ & $\begin{array}{c}\text { Penurunan } \\
\text { Mas5a }(\%)\end{array}$ & $\begin{array}{c}\text { Puncak } \\
\text { Endotermik } \\
\left({ }^{\circ} \mathrm{C}\right)\end{array}$ \\
\hline A1 & $40-102$ & 11,4 & 47,4 & $239-339$ & 32,31 & 286 \\
B1 & $40-108$ & 14,7 & 47,4 & $228-327$ & 34,61 & 269 \\
C1 & $40-119$ & 13,0 & 47,3 & $210-321$ & 30,17 & 257 \\
C2 & $40-113$ & 12,5 & 47,3 & $204-304$ & 30,96 & 257 \\
C3 & $40-119$ & 12,0 & 47,3 & $216-309$ & 29,11 & 257 \\
\hline
\end{tabular}

Nilai fluks membran berbanding terbalik terhadap fungsi waktu, semakin bertambahnya waktu nilai fluks suatu membran cenderung turun. Penurunan berlangsung terus menerus hingga tercapai keadaan tunak. Gejala tersebut dapat terjadi akibat adanya polarisasi konsentrasi dan atau terjadinya fouling pada permukaan membran yang dilewati oleh suatu larutan.

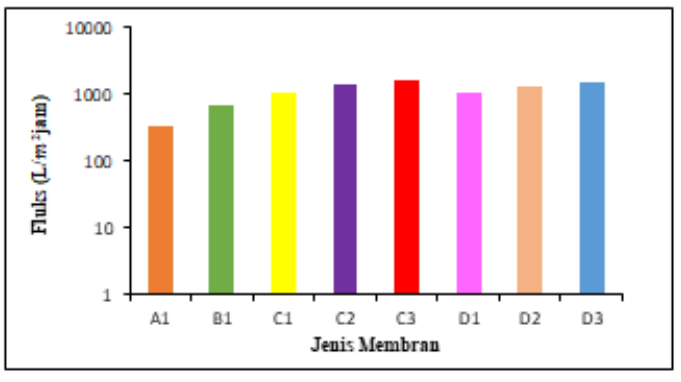

a

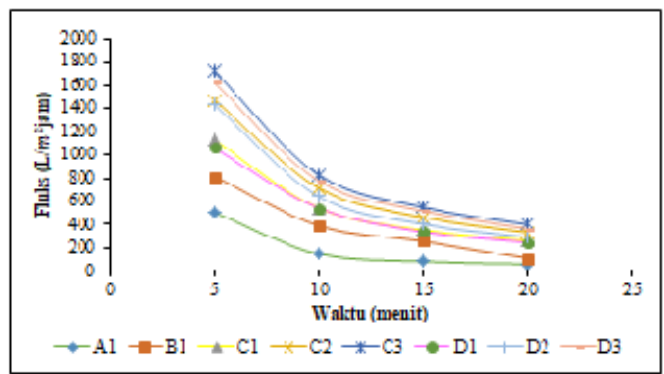

$\mathrm{b}$

Gambar 7. Grafik Fluks Membran (a) Fluks aquades membran terhadap waktu (b)

\section{KESIMPULAN}

Telah diperoleh senyawa turunan kitosan melalui modifikasi gugus mengunakan reaksi paduan dengan PEG dan reaksi cangkok dengan heparin, dibuktikan dengan kesesuaian antara serapan gugus fungsi dengan bilangan gelombang pada uji FTIR. Membran modifikasi yang dihasilkan mampu meningkatkan kekuatan terhadap pengaruh $\mathrm{pH}$ dari range $\mathrm{pH}$ 5-11, 
peningkatan hidrofilisitas, peningkatan serapan air sebesar 2 kali lipat, porositas, kekuatan mekanik membran, fluks transpor sebesar 2 kali lipat dibandingkan membran kitosan murni dari informasi uji karakteristik membran.

\section{UCAPAN TERIMAKASIH}

Terimakasih kepada Universitas Diponegoro melalui pendanaan dalam Skim Penelitian Riset Pengembangan dan Penerapan (RPP) dengan No kontrak : 385 - 50/UN7.P4.3/PP/2019.

\section{DAFTAR PUSTAKA}

Burggraaf, A., Cot, L., Kesting, R. dan Fritzsche, A., 2000, Future Developments

Lusiana, R. A., Pambudi, G. A., Sari, F. N., Widodo, D. S., Khabibi, K. dan Isdadiyanto, S., 2019, Grafting of Heparin on Blend Membrane of Citric Acid Crosslinked Chitosan/Polyethylene Glycol-Poly Vinyl Alcohol (PVA-PEG). Indonesian Journal of Chemistry 19(1).

Lusiana, R. A., Dwi Siswanta, and Mudasir. 2016. Preparation of Citric Acid Crosslinked Chitosan/Poly(Vinyl Alcohol) Blend Membranes for Creatinine Transport, Indones. J. Chem. 16 (2), $144-150$.

Lusiana, R. A., dan Pranoto, W.P. 2018. Membran Kitosan Termodifikasi Tripolifosfat-Heparin Dan Aplikasinya Pada Permeasi Urea Dan Kreatinin. Anal.Environ.Chem. Vol. 3(1), 1121.

Kiswandono, A.K. 2016. Review: Metode Membran Cair untuk Pemisahan Fenol. Anal.Environ.Chem. Vol. 1(1), 74-88.

Zeng, M., Fang, Z. dan Xu, C., 2004, Novel Method of Preparing Microporous Membrane by Selective Dissolution of Chitosan/Polyethylene Glycol Blend Membrane. Journal of Applied Polymer Science 91(5): 2840-2847.

Huang, X. J., Guduru, D., Xu, Z. K., Vienken, J. dan Groth, T., 2011, Blood Compatibility and Permeability of Heparin-Modified Polysulfone as Potential Membrane for Simultaneous Hemodialysis and Ldl Removal. Macromolecular bioscience 11(1): 131-140.

Martins, J. T., Cerqueira, M. A. dan Vicente, A. A., 2012, Influence of A-Tocopherol on Physicochemical Properties of Chitosan-Based Films. Food Hydrocolloids 27(1): 220227.

doi: http://dx.doi.org/10.23960/aec.v4.i2.2019.p01-13

Anal.Environ.Chem.Anal.Environ.Chem. 